\title{
A pocket guide to electronic laboratory notebooks in the
}

\section{academic life sciences [version 1; peer review: 4 approved]}

\section{Ulrich Dirnagl(i)1-5, Ingo Przesdzing ${ }^{1}$}

\author{
${ }^{1}$ Department of Experimental Neurology and Center for Stroke Research Berlin (CSB), Charité Universitätsmedizin Berlin, Berlin, \\ 10117, Germany \\ ${ }^{2}$ German Center for Neurodegenerative Diseases, Berlin, 10117, Germany \\ ${ }^{3}$ German Center for Cardiovascular Diseases (DZHK), Berlin, 10117, Germany \\ ${ }^{4}$ Excellence Cluster NeuroCure, Berlin, 10117, Germany \\ ${ }^{5}$ Berlin Institute of Health, Berlin, 10117, Germany
}

V1 First published: 04 Jan 2016, 5:2

https://doi.org/10.12688/f1000research.7628.1

Latest published: 04 Jan 2016, 5:2

https://doi.org/10.12688/f1000research.7628.1

\section{Abstract}

Every professional doing active research in the life sciences is required to keep a laboratory notebook. However, while science has changed dramatically over the last centuries, laboratory notebooks have remained essentially unchanged since pre-modern science. We argue that the implementation of electronic laboratory notebooks (eLN) in academic research is overdue, and we provide researchers and their institutions with the background and practical knowledge to select and initiate the implementation of an eLN in their laboratories. In addition, we present data from surveying biomedical researchers and technicians regarding which hypothetical features and functionalities they hope to see implemented in an eLN, and which ones they regard as less important. We also present data on acceptance and satisfaction of those who have recently switched from paper laboratory notebook to an eLN. We thus provide answers to the following questions: What does an electronic laboratory notebook afford a biomedical researcher, what does it require, and how should one go about implementing it?

Keywords

Code of Federal Regulations Title 21, Documentation, Data storage, Good Scientific Practice, Good Laboratory Practice, Laboratory information management systems, Software

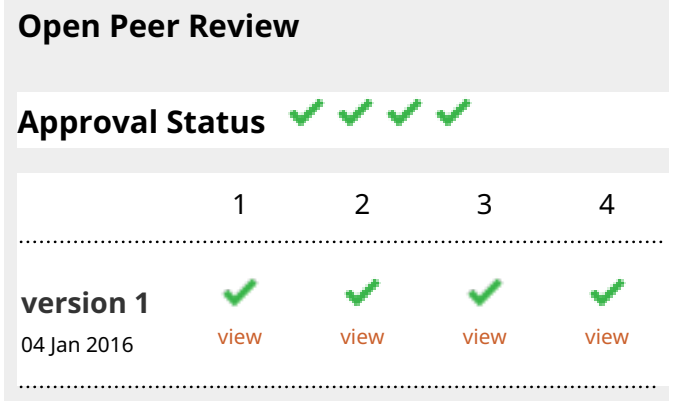

1. Thomas A. Kent, Baylor College of Medicine, Houston, USA

2. Christoph Kleinschnitz, University of Essen, Würzburg, Germany

Eva Geuß, University Hospital Würzburg, Würzburg, Germany

3. Barry W. McColl, The University of Edinburgh, Edinburgh, UK

4. Ádám Dénes, Hungarian Academy of Sciences, Budapest, Hungary Any reports and responses or comments on the article can be found at the end of the article.

This article is included in the INCF gateway. 
Corresponding author: Ulrich Dirnagl (ulrich.dirnagl@charite.de)

Competing interests: No competing interests were disclosed.

Grant information: Supported by the German Research Foundation (Exc 257), the Federal Ministry of Education and Research (01 EO 08 01), the Herman and Lilly Schilling Foundation, and intramural funding by the Berlin Institute of Health (all to UD).

Copyright: $\odot 2016$ Dirnagl $U$ and Przesdzing I. This is an open access article distributed under the terms of the Creative Commons Attribution License, which permits unrestricted use, distribution, and reproduction in any medium, provided the original work is properly cited.

How to cite this article: Dirnagl $U$ and Przesdzing I. A pocket guide to electronic laboratory notebooks in the academic life sciences [version 1; peer review: 4 approved] F1000Research 2016, 5:2 https://doi.org/10.12688/f1000research.7628.1

First published: 04 Jan 2016, 5:2 https://doi.org/10.12688/f1000research.7628.1 
In this article we argue that the implementation of electronic laboratory notebooks $(\mathrm{eLN})$ in academic research is overdue, and we provide researchers and their institutions with the background and practical knowledge to select and initiate the establishment of an eLN in their laboratories. Based on our own extensive experience in moving from laboratory notebooks (LN) to eLN, we try to answer the following questions: What does it afford you, what does it require, and how should you go about implementing it?

Every professional doing active research in the life sciences is required to keep a $\mathrm{LN}$. This is imperative for group leaders, postdocs, students, as well as technicians. LNs are the core element of record keeping, data management, and initial analysis and interpretation of results in research. Details of its specifications, storage, etc. are laid down in institutional, national, as well as international codes of conduct for research integrity and good laboratory practice ${ }^{1}$. These codes usually stipulate sequentially numbered and bound pages, use of permanent ink, storage for a minimum of 10 years; they often require that entries be signed and dated by a witness. The use of LN has a long history, which parallels the development of modern science since the Renaissance. However, while science has changed dramatically over the last centuries, LNs have remained essentially unchanged since pre-modern science $^{2}$ (Figure 1). This is highly remarkable for a number of reasons. For one, most of the data gathered is no longer analog, but digital. Gone are the days when researchers read numbers from instrument for transfer to the LN. Today there is a complex mixture of (often repetitive) protocols, digital images, links to large data files, etc. In addition, the recent realization that there is a 'reproducibility' crisis in the life sciences, and an increasing number of high profile cases of research misconduct and subsequent retraction of publications has put record keeping in the spotlight. It is therefore not surprising that the pharmaceutical industry, with its superior resources and regulatory pressures (e.g. Code of Federal Regulations Title $21^{3}$ ) has moved to eLNs. Many researchers and institutions in academia now realize that the implementation of eLNs is overdue. However, only a tiny fraction of university laboratories are using them. Major hurdles for implementation appear to include ignorance about practical issues, perceived scarcity of available options, and a lack of resources. As part of the implementation of an ISO 9001-certified quality management system, our department (Department of Experimental Neurology) has recently moved from LNs to an eLN. At this department with approximately 100 students, researchers, technicians we carry out multi-professional academic research in preclinical biomedicine with such standard approaches and techniques as in vivo and and in vitro modeling of disease, cell biology, molecular biology, biochemistry, as well as imaging (from multiphoton microscopy to magnetic resonance imaging). We therefore believe that our experience is applicable to a wide range of research operations in the life sciences.

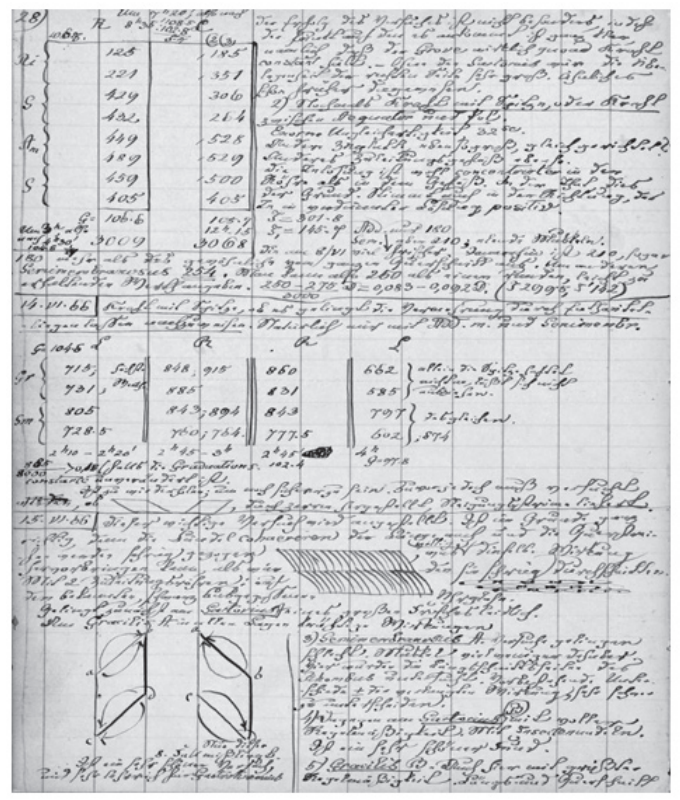

A

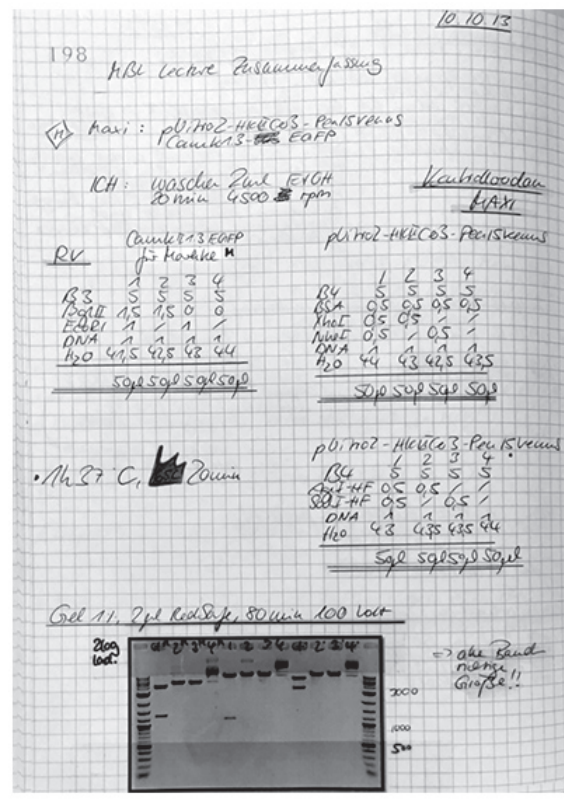

B

Figure 1. Laboratory notebooks have remained essentially unchanged throughout the last centuries. A: Page from the laboratory notebook of the father of experimental electrophysiology, Emil Dubois-Raymond (7 November 1818 - 26 December 1896). [Staatsbibliothek Berlin, 1865-1868, XIII, 22. VII. 65-9. VI. 68, reproduced with permission]. B: Pages from a contemporary laboratory notebook from the laboratory of the authors. 


\section{Why you will switch to an eLN}

We believe that the question is not whether eLNs will become standard or even required in the academic life sciences, but when. The advantages of an eLN are as obvious as the disadvantages of the conventional $\mathrm{LN}^{4}$. Most of the original data obtained in laboratories worldwide is already digital and can easily be integrated or linked to the eLN. eLNs foster collaboration, as protocols, data and concepts can be shared within or between groups. Entries can be time stamped, changes are recorded, versions controlled. Protocols used frequently can simply be integrated as templates. Project progress and eLN use can be easily monitored by group or project leaders. eLNs are searchable, archiving is simple, and copies are easily made for the institution and the individual researcher, many of whom will leave the institution at some point. These features include just a few of the functionalities which are already available in eLNs and are completely absent in a LN. Future eLNs will provide further benefits, including direct data links to standard laboratory hardware through an application programming interface (API) and automatic alerts when instruments are malfunctioning or not calibrated, or direct links to open data repositories (such as Figshare or Dryad). LNs, on the other hand, tend to get lost, must stay within the institution, which in turn has to keep track of them and is charged with keeping reliable records of LNs, storing them and enabling access for at least 10 years.

\section{Selecting an eLN}

If you are contemplating a switch to eLNs, you first need to decide what you expect from it, and match this with your resources (see also below). Table 1 summarizes the principal features of three different categories of eLNs. The simplest form ('do-it-yourself' DIY - type) is a word processor or note-taking system ${ }^{5}$. It is cheap, easy to use, and has many of the features a conventional LN; its major drawback is its lack of any kind of audit trail or certification. Such DIY-eLNs thus do not even conform to the standards of classical LNs, and therefore are not a serious option for their replacement. Dedicated eLNs have many additional features. Importantly most commercially available eLNs are compliant with the Code of Federal Regulations Title 21 (CFR Title 21) of the US Food and Drug Administration (FDA). CFR Title 21 part 11 sets rigorous specifications for electronic record keeping, including electronic signatures and version control. CFR Title 21 is a must if protection of intellectual property or use of the records for regulatory processes (such as FDA) is a factor ${ }^{6}$. Dedicated eLNs also allow complex rights management within institutes and workgroups, and can integrate original data. High-end systems include all the features of an eLN, but also function as laboratory information management systems (LIMS), facilitating inventory management or direct link to laboratory equipment (such as microscopes, sequencers, etc.). Not surprisingly, while DIY-eLNs are very easy to use, the increasing

Table 1. Comparison of specifications of three different types of eLNs. Note that ease of use and the availability as well as power of features of eLNs are inversely related.

\begin{tabular}{|c|c|c|}
\hline $\begin{array}{l}\text { Basic systems, such as repurposed } \\
\text { word processors (e.g. Word) or note } \\
\text { taking systems (e.g. Evernote) }\end{array}$ & $\begin{array}{l}\text { Dedicated, commercial eLNs (e.g. } \\
\text { iLabber, Labfolder, eCat) }\end{array}$ & $\begin{array}{l}\text { High end systems (eLNs including a } \\
\text { LIMS, e.g. IBDS E-WORKBOOK, ILAB } \\
\text { Laboratory Execution System) }\end{array}$ \\
\hline $\begin{array}{l}\text { Ability to enter text as in conventional } \\
\text { handwritten LN }\end{array}$ & $\begin{array}{l}\text { All features from the basic systems plus } \\
\text { (see below) }\end{array}$ & $\begin{array}{l}\text { All features from the dedicated, } \\
\text { commercial systems plus (see below) }\end{array}$ \\
\hline $\begin{array}{l}\text { Notes can be made available on } \\
\text { multiple devices (stored in the cloud) }\end{array}$ & Freehand drawing & $\begin{array}{l}\text { Inventory management: } \\
\text { complete tracking of samples/reagents } \\
\text { through all experiments }\end{array}$ \\
\hline Attach files to notes & $\begin{array}{l}\text { Complex rights management (with roles } \\
\text { and individual rights) }\end{array}$ & $\begin{array}{l}\text { Workflows for certain samples, tasks, } \\
\text { experiments }\end{array}$ \\
\hline Visualization of attachments in the note & $\begin{array}{l}\text { 21CFR } 11 \text { compliance: } \\
\text { All previous versions of a note are stored/ } \\
\text { changes are logged (full audit trail) } \\
\text { Prevents deletion of notes by their author } \\
\text { Electronic signatures for completed } \\
\text { notes } \\
\text { Witnessing and freezing (makes note } \\
\text { immutable after the author and a witness } \\
\text { have signed it) }\end{array}$ & $\begin{array}{l}\text { Direct link to laboratory equipment } \\
\text { (e.g. microscopes, spectrometers, } \\
\text { sequencers): } \\
\text { Automatic delivery of raw data by device } \\
\text { Delivery of metadata (e.g. date of last } \\
\text { calibration) from device }\end{array}$ \\
\hline Annotation of attachments (e.g. images) ${ }^{\star}$ & $\begin{array}{l}\text { Extensions/API for customization } \\
\text { available }\end{array}$ & Analysis of raw data within the system \\
\hline Search within the written text & Assigning of tasks between colleagues* & $\begin{array}{l}\text { Data mining (aggregate and cluster } \\
\text { structured data) }\end{array}$ \\
\hline Search in attachments* & $\begin{array}{l}\text { Inventory management: } \\
\text { Only amount and location of samples/ } \\
\text { reagents }\end{array}$ & \\
\hline $\begin{array}{l}\text { Notes can be shared with colleagues/ } \\
\text { collaborators* }\end{array}$ & & \\
\hline
\end{tabular}

Abbreviations: API, Application programming interface; 21 CFR 11, code of federal regulations title 21 part 11; LIMS, Laboratory Information Management System. *Indicates that this feature is available in some systems of this category only. 
functionality of dedicated eLNs and eLNs integrated into LIMS comes at the price of growing complexity in its use. This might be a particular concern when non-academic personnel need to work with the eLN. Another issue is language - the user menus and help functions of practically all commercially available eLNs are in English; only a few allow the user to switch to other languages. Again, this may, in combination with a complex functionality, pose problems, and hamper the acceptance of the eLN in non-academic and less tech-savy work environments. Several articles have reviewed and compared various eLNs?

\section{What you need to get started}

For the individual researcher planning to move to an eLN very few requirements exist. Several open source eLNs are freely available (e.g. 8). Some companies offer basic eLN versions for a limited number of users and only as cloud based solutions free of charge (e.g. Labfolder), but for full feature commercial solutions license fees will apply. If a whole workgroup, department, or institution wants to set up an eLN, it gets more complicated. First and foremost, one needs to make sure that the eLN will be accepted by the users. This is not trivial, as many researchers and technicians have been socialized using a conventional LN. They may not be familiar with the many additional useful features provided by an eLN, and are confronted with the challenge and potential distraction of learning how to use a new tool.

To investigate the willingness of staff in a large academic research institution to switch from paper $\mathrm{LN}$ to ELN, and to find out what they expect from an ELN, we have surveyed students, technicians, and scientists. We also queried the staff of a research department in the process of switching from LN to ELN. Across professions and career stages the preference was for an intuitive and easy to use interface, a better integration of digital content, use of templates, and the ability to structure notes better. Features considered much less relevant were annotation and freehand drawing, the ability to use mobile devices, or saving time. On an individual level, user expectations and ratings did not substantially change when they progressed from eLN-naive to eLN. More than $70 \%$ of those not using an eLN were eager to start working with one, while almost $82 \%$ of those already using an eLN now prefer it over the paper version. For details and full results of the surveys, see Supplementary materials 1-4. Although our survey revealed that users of paper laboratory notebooks had a strong motivation for switching to an eLN and a high satisfaction rate for eLNs among those using it, we recommend not to enforce the switch to an eLN. Rather, it should be offered as an opportunity to those who are interested, and scale up its implementation as more group members join in. Sceptics will be able to observe its use, and will very likely want to become users within a short time period.

Another important issue relates to information technology (IT). For workgroups and institutes, the program and data storage will need to run on a server, with local clients, or through a browser interface. Obviously, every lab member using the eLN needs access to a computer. Most eLNs can run on mobile devices and can therefore be taken to the bench or site of experiment even if no computer is present at the site. This requires a wireless connection (WLAN) covering the laboratory or institution. Data can be linked to the eLN by assigning the file and drive name where it is stored. More conveniently, clickable links can directly connect to the data, but this requires that the eLN is physically integrated into the data management structure of the institution. All of this means that in most cases the selection and installation of an $\mathrm{EN}$ from a group level on needs the support of the institutional IT department. They will also be responsible for upgrades, backups, etc. For large-scale installations within whole departments and institutions, training and support contracts need to be considered. Table 2 gives an overview of the requirements.

\section{Obstacles and pitfalls}

At present no standard exists for eLNs, and the market is still evolving, so that none of the software makers can guarantee support and further development of their eLN beyond a couple of years. As of now there are no standards for data annotation and integration,

Table 2. Prerequisites for the implementation of an eLN. Note that prerequisites vary with type of eLN and number of users (see Table 1).

\begin{tabular}{|c|c|}
\hline Requirement & Comment \\
\hline Staff willing and able to use the eLN & $\begin{array}{l}\text { Note that most systems use the English language for menus and help } \\
\text { functions, and user training may be needed for complex LIMS-eLNs }\end{array}$ \\
\hline $\begin{array}{l}\text { IT infrastructure: } \\
\text { Computer access for all users } \\
\text { Mobile devices for all users and WLAN } \\
\text { Server to host ELN } \\
\text { Server to host databases and uploaded data } \\
\text { Backup system and load balancer }\end{array}$ & $\begin{array}{l}\text { Only if used on mobile devices } \\
\text { Required unless only few individual users use cloud-based system } \\
\text { Depends on number of users/volume of data }\end{array}$ \\
\hline $\begin{array}{l}\text { Personnel for maintenance } \\
\text { On-site support } \\
\text { User training } \\
\text { Administrator of eLN/server }\end{array}$ & Relevant for larger installations in workgroups and institutions \\
\hline $\begin{array}{l}\text { Financial } \\
\text { License fees or costs for the development custom system } \\
\text { Costs for the IT infrastructure (especially storage) } \\
\text { Costs for the staff supporting and administrating the eLN }\end{array}$ & $\begin{array}{l}\text { Some commercial systems have basic cloud-based solutions that are } \\
\text { free of charge; some systems are unrestricted freeware. }\end{array}$ \\
\hline
\end{tabular}


therefore migration between different platforms may be difficult or even impossible. In a worst-case scenario (eLN provider goes out of business, no further development or support), the existing eLNs must be saved to pdf-format (including time stamps, addresses linking to stored data etc.), or to $\mathrm{html} / \mathrm{xml}$ formats, as this will help retain some of the functionality. Such a feature should be mandatory, and is provided by most eLNs. This would essentially mean reverting to a conventional lab book, but the pdf would still provide extra features such as searchability and ease of copying and storage. For eLNs evolving on an open source platform, termination of support of proprietary software is not an issue. However, development or bug fixing of open source software may also be terminated. In addition, such systems may have less support than commercial systems, and support be restricted to tech-savy users or environments with programming capabilities. Another issue relates to the complexity and wealth of functions provided in particular by the high-end eLNs (often part of a LIMS). If using the eLN becomes too complex or restrictive, users may start recording their work outside the eLN. Finally, committing to long-term license fees may be a problem, in particular for individual researchers who may have only fluctuating financial or institutional support.

\section{Conclusion and recommendations}

How biomedical scientists take notes and document their work has not changed much over the last 200 years: They write with a pen in a bound, paginated laboratory notebook. The only major modification is that today, printouts or images of results are often attached (Figure 1). Data, however, is meanwhile almost exclusively digital, and digital technology provides a plethora of tools for recording, annotating, sharing, processing, and storing all the information that cumulatively drives progress in the life sciences. Scientists use computers for everything and everywhere, privately and professionally, except for documenting their research, experiments, and laboratory procedures. Several reasons may account for the astounding survival of the paper LN. It is a robust and easy to handle 'technology', which has been handed down over generations of scientists. At the same time, the emerging eLN market has been dominated by expensive solutions for research and development in large life science companies. Standards for data annotation, exchange or export between different eLN platforms have not yet evolved. There is a hesitation to commit to a specific product that may no longer be supported when the company goes out of business. The inertia of scientists to abandon their cheap and time-honored record keeping system, despite its numerous disadvantages and despite the obvious advantages of electronic solutions, has hampered the development of mature and affordable products for the academic sector. This has led to a vicious circle: Lack of interest on the part of scientists has frustrated the development of dedicated software. Over the last few years, the situation has slowly but substantially changed, and mature and affordable (or even free) eLNs are available. Scientists who overcome their reservation and exchange their LN for an eLN regularly become avid supporters after a short learning period, praising functionalities like group collaboration, use of templates, embedding of data, scheduling, access to the eLN from any computer world-wide, etc. In addition, group leaders and organizations value enhanced documentation and version control, improved supervision of record keeping, as well as backup and archiving of records.

\section{Box 1. Recommendations}

Ensure willingness of staff to use the novel record keeping technology (ease of use, language of menus).

Clearly define the functionalities that you expect from the eLN. Do not get lost in the almost limitless portfolio of potential functionalities. Remember: You probably just want to replace your paper LN, and not install a new word processor, graphics editor, or groupware system

Although you may not be aware of it now, you probably want a product which complies to legal requirements like 21CFR11, as well as good scientific practice (full audit trial, restriction on deletion of data, timestamps, ability to freeze and sign entries, among others).

Unless you will be the only user, flexible and hierarchical rights management is very important.

The system needs to be able to tag, filter and search entries. Organization of data in eLN in projects, subprojects, milestones, etc. is a must

Make sure that all entries, imported data, and links can be exported to a generic format (pdf, zip, xIm, etc.) for backup and reporting as well as allowing a bailout in case the maker of the software stops development, or your funds to pay for licence fees run dry.

Enlist the support of your IT department at an early stage (selection of particular eLN)

Beware of hidden costs (hardware like server, backup devices; on-site support and user training, if applicable etc.)

Besides serving all the obvious functions of a paper LN, eLNs facilitate scientists' workflow (quick creation and editing of experiments) and collaboration (sharing and reusing information, independent of location, harmonization of work practices). They allow the integration of data, images, files, etc. and can already read data directly from instruments. They eliminate the need to transcribe or cut-paste data from one system to another, thereby avoiding transcription errors. Templates and boilerplate text modules prevent tedious rewriting. eLNs facilitate the retrieval of data or information over long periods of time, improve data quality (legibility), and allow the detailed reconstruction of individual experiments. They facilitate the mobility of researchers. Last, but not least, eLNs promote compliance with Guidelines on Good Laboratory Practice (GLP) and Good Scientific practice, and help intellectual property protection by their compliance to 21CFR 11 . We have no doubt that eLNs will become standard in most life science laboratories in the near future.

\section{Author contributions}

UD prepared the first draft of the manuscript. UD and IP designed the survey, which was conducted and analyzed by IP. UD and IP were involved in the revision of the draft manuscript and have agreed to the final content. 
Competing interests

No competing interests were disclosed.

Grant information

Supported by the German Research Foundation (Exc 257), the Federal Ministry of Education and Research (01 EO 08 01), the
Herman and Lilly Schilling Foundation, and intramural funding by the Berlin Institute of Health (all to UD).

Acknowledgements

We thank Dr. Niko Offenhauser and Sebastian Major for their help in setting up the eLN.

\section{Supplementary material Supplementary material 1.}

Results of an anonymous survey at the Department of Experimental Neurology.

Click here to access the data.

\section{Supplementary material 2.}

Results of an anonymous survey at Charité Universitätsmedizin Berlin.

Click here to access the data.

\section{Supplementary material 3.}

Printout of the questions of the survey at the Department of Experimental Neurology.

Click here to access the data.

\section{Supplementary material 4.}

Printout of the questions of the survey at Charité Universitätsmedizin Berlin.

Click here to access the data.

1. The European Code of Conduct for Research Integrity. Retrieved Oct 2015 Reference Source

2. Kanare HM: Writing the Laboratory Notebook. Amercian Chemical Society, Washington DC, 1985. Retrieved Oct 2015. Reference Source

3. CFR Title 21. US FDA. Retrieved Oct 2015 Reference Source

4. Nussbeck SY, Weil P, Menzel J, et al.: The laboratory notebook in the $21^{\text {st }}$ century: The electronic laboratory notebook would enhance good scientific practice and increase research productivity. EMBO Rep. 2014; 15(6): $631-4$

PubMed Abstract | Publisher Full Text | Free Full Text
5. Walsh E, Cho I: Using Evernote as an electronic lab notebook in a translational science laboratory. J Lab Autom. 2013; 18(3): 229-34. PubMed Abstract | Publisher Full Text

6. Nickla JT, Boehm MB: Proper laboratory notebook practices: protecting your intellectual property. J Neuroimmune Pharmacol. 2011; 6(1): 4-9. PubMed Abstract | Publisher Full Text | Free Full Text

7. Rubacha M, Rattan AK, Hosselet SC: $\mathbf{A}$ review of electronic laboratory notebooks available in the market today. $J$ Lab Autom. 2011; 16(1): 90-8. PubMed Abstract | Publisher Full Text

8. Voegele C, Bouchereau B, Robinot N et al: A universal open-source Electronic Laboratory Notebook. Bioinformatics. 2013; 29(13): 1710-2. PubMed Abstract | Publisher Full Text 


\section{Open Peer Review}

\section{Current Peer Review Status:}

\section{Version 1}

Reviewer Report 14 January 2016

https://doi.org/10.5256/f1000research.8214.r11788

(C) 2016 Dénes Á. This is an open access peer review report distributed under the terms of the Creative Commons Attribution License, which permits unrestricted use, distribution, and reproduction in any medium, provided the original work is properly cited.

\section{Ádám Dénes}

MTA Institute of Experimental Medicine, Hungarian Academy of Sciences, Budapest, Hungary

In this article the authors present their views on laboratory record keeping procedures and argue that electronic laboratory notebooks (eLN) would be most suitable to support modern scientific research replacing the traditional, paper based version. One major strength of this paper is the personal experience of the authors with eLN from their own department. As it comes clear from the text, researchers are often reluctant to switch to eLN despite their advantages over the old fashioned laboratory notebooks. The authors arguments for using eLN are well taken: original data generated in laboratories are mostly digital, storage of large files, protocols or images requires electronic data management anyway, whilst data sharing or searching large databases, protocols becomes much easier if using eLN. In addition, eLN run on portable devices and entries can be time stamped and changes recorded, which is required by the scientific community and regulatory pressures. Whilst the authors' preference is obvious for eLN, they are cautious with their recommendations and clearly outline the potential pitfalls of eLN as well.

In my opinion, the following issues might deserve a short explanation:

What is the level of detail researchers should record in eLN? In the case of standard LN, complex data files and large figures mostly remain electronic, whilst some figures, tables, analysis results and conclusions are incorporated into the LN. However, software running on dedicated machines (flow cytometers, imaging devices, etc) generate large files that are only partially extracted in text, PDF or other forms due to their incompatibility with common word processing tools. Should eLN users attempt to incorporate some of these data into eLN considering limitations in storage space, or such files should remain stored and analysed as earlier?

How safe do the authors feel keeping most of their research data in an organized manner in eLN using cloud-based systems or large databases that are available from external servers or institutions? Are there measures large research units should consider before switching to eLN to support the protection of intellectual property or their patent applications?

Overall, I find this article very useful and informative. I suspect that in the near future most research labs will not be able to avoid using eLN due to a number of reasons explained clearly in 
the paper. Practical information from experienced users will greatly support the willingness of researchers to start using eLN and this could also contribute to dealing with reproducibility issues in the future.

Competing Interests: No competing interests were disclosed.

\section{I confirm that I have read this submission and believe that I have an appropriate level of expertise to confirm that it is of an acceptable scientific standard.}

Reviewer Report 08 January 2016

https://doi.org/10.5256/f1000research.8214.r11785

(C) 2016 McColl B. This is an open access peer review report distributed under the terms of the Creative Commons Attribution License, which permits unrestricted use, distribution, and reproduction in any medium, provided the original work is properly cited.

\section{Barry W. McColl}

The Roslin Institute, Royal (Dick) School of Veterinary Studies, The University of Edinburgh, Edinburgh, UK

The authors present a persuasive argument for replacing conventional lab notebooks with electronic versions (eLNs). Crucially, they outline the current drawbacks of conventional lab books in the current age and why there is a need to consider alternatives. One comment would be that the authors could perhaps have indicated if alternatives other than the systems mentioned in the article exist?

The benefits of adopting eLNs described seem clear and comprehensive but importantly the potential weak points are also considered to give some balance. A similarly balanced tone is evident in discussion of the willingness of researchers to adopt eLNs and their reaction to doing so. Thus while the article is clearly presenting the authors' favoured opinion they also reflect on alternative views.

As commented on by the authors, adopting an electronic system particularly in larger departments or organisations will need the appropriate IT infrastructure and support. While the authors surveyed opinions from researchers it might also have been informative to gauge and record opinion from IT professionals as to some of the practical issues of particular relevance to lab personnel.

Overall, this article is very well structured and presents a helpful and informative perspective and primer on this emerging issue.

Competing Interests: No competing interests were disclosed.

I confirm that I have read this submission and believe that I have an appropriate level of expertise to confirm that it is of an acceptable scientific standard. 
Reviewer Report 06 January 2016

https://doi.org/10.5256/f1000research.8214.r11789

(C) 2016 Kleinschnitz C et al. This is an open access peer review report distributed under the terms of the Creative Commons Attribution License, which permits unrestricted use, distribution, and reproduction in any medium, provided the original work is properly cited.

\section{Christoph Kleinschnitz}

Department of Neurology, University of Essen, Würzburg, Germany

Eva Geuß

University Hospital Würzburg, Würzburg, Germany

Dirnagl and Przesdzing provide a highly innovative and comprehensive summary for the use of electronic laboratory notebooks (eLNs) in life science research. They highlight advantages of eLNs over traditional hand written LNs, comment on possible obstacles and inform readers about distinct features/specification of different types of eLN systems, e.g. complex rights management, integration of original data, direct link to laboratory equipment etc. In addition, they offer a stepby-step instruction of how to establish eLN systems in everyday laboratory practice based on the successful implementation of eLNs in their own institution. From an internal survey of their staff (scientist, students, technicians) they deduce which features of eLN systems were considered most desirable and which ones were regarded less relevant.

In total, the article is highly informative for any researcher working in the life science field and is a very well suited guide for everybody who plans to switch from LN to eLN.

Competing Interests: No competing interests were disclosed.

We confirm that we have read this submission and believe that we have an appropriate level of expertise to confirm that it is of an acceptable scientific standard.

Reviewer Report 05 January 2016

https://doi.org/10.5256/f1000research.8214.r11787

(C) 2016 Kent T. This is an open access peer review report distributed under the terms of the Creative Commons Attribution License, which permits unrestricted use, distribution, and reproduction in any medium, provided the original work is properly cited.

\section{Thomas A. Kent}

Department of Neurology, Stroke Outcomes Laboratory, Baylor College of Medicine, Houston, TX, USA

This is a valuable description of the author's experience with electronic laboratory notebook implementation within their department. There can be much value in educating the broader 
scientific community with respect to both their experience, the experience of those they surveyed and the available options for the researcher.

The manuscript can be improved through better definition of terms and procedures related to the eLN with which the average laboratory scientist may not be familiar. Some examples follow:

The title is appropriate and the abstract is a good summary.

\section{Introduction:}

The authors department pursued ISO 9001-certified laboratory quality management system. Could they expound on what this means, why they chose to pursue it and what it entails? What kind of resources did they devote to this and what did they hope to gain in return?

\section{"Why you will switch to an eLN"}

While suitably provocative, perhaps reword the section title as "Why you will switch to an eLN" seems to put the answer before the research is presented. Perhaps a more neutral statement might not appear that the conclusion has been pre-judged.

In this section, the authors list several advantages to an eLN, including for example, that original data can be "easily integrated or linked to the eLN". I assumed this meant a direct link to the eLN from the laboratory equipment, but later in this paragraph, the authors describe such a direct link as in the future. Could they then explain how data is easily integrated in the eLN? This question may be a major one for those used to using written notebooks where printouts are often physically attached. And if the data is not directly loaded into the eLN, how is it searchable? Are they scanning data through OCL or some other method? Some details would help the reader visualize how this system might help them.

\section{"What you need to get started"}

This is a well written section with a nice summary Table of the different options. If possible, it might be beneficial to discuss costs, perhaps within an order of magnitude for the different systems, although not if this is proprietary information.

With respect to the surveys, while the heat maps are useful, it is not easy to follow whether there is a pattern to the different features. Perhaps an analysis using the highest/lowest scores graphically might be more helpful. It does not appear that any pitfalls were included in the questions. In the article, the authors later discuss possibility of loss of technical support, updates and possibility that the sponsor may go out of business. It is not clear that the survey included that possibility and how the respondents might have answered. I would consider this a modest weakness, but would like to hear some comment from the authors.

\section{"Obstacles and pitfalls"}

This is an excellent section that is most useful to the potential purchaser of a system and what are the minimum requirements that should be available should the support be terminated.

This is an important section. Are there alternatives? For example, upfront costs and uncertain future of any wholly integrated platform are reasons that some labs have set up their own cloud based systems, although without all the functionality of an integrated system and without FDA certification, but the data can be easily referenced to physical lab books and as such provide some 
of the advantages of a whole integrated system.

I have a question for the authors: Do they think that "electronic laboratory notebook manager" may become a new, sought after, position analogous to the "network manager" that is needed even though there are multiple commercial products available and standards widely accepted? Perhaps the pharma experience on how to manage a large, integrated eNL might be helpful here if the authors are aware of them, or perhaps they could describe how at the department whether the management of the eLN is the responsibility of specific individuals.

"Conclusions and recommendations"

This is a good summary of the authors' thoughts. Perhaps a little harsh with the term "inertia of scientists", there may be many reasons that scientists have not embraced eLN in their work, particularly if it is a small laboratory or one strapped for resources other than inertia.

The authors only once mention the important issue of need for restrictions on alteration of data, and only in the Box 1. Perhaps some mention of this issue would be helpful in the text as well.

The final list of recommendations is an excellent primer for exploring the possibility of an eLN.

I commend the authors for their efforts to increase the visibility of such systems and providing their experience and perspective on this topic.

Competing Interests: No competing interests were disclosed.

I confirm that I have read this submission and believe that I have an appropriate level of expertise to confirm that it is of an acceptable scientific standard.

The benefits of publishing with F1000Research:

- Your article is published within days, with no editorial bias

- You can publish traditional articles, null/negative results, case reports, data notes and more

- The peer review process is transparent and collaborative

- Your article is indexed in PubMed after passing peer review

- Dedicated customer support at every stage

For pre-submission enquiries, contact research@f1000.com

F1000Research 